\title{
Analisis beban dan tingkat pencemaran di Perairan Dumai, Provinsi Riau
}

\author{
F. Ariani $1^{*}$, H. Effendi², Suprihatin ${ }^{3}$ \\ 1Program Studi Teknologi Penangkapan Ikan, Sekolah Tinggi Perikanan dan Kelautan Matauli, Tapanuli \\ Tengah, Indonesia \\ 2Pusat Penelitian Lingkungan Hidup, IPB University, Bogor, Indonesia \\ ${ }^{3}$ Departemen Teknologi Industri Pertanian, IPB University, Bogor, Indonesia
}

\begin{abstract}
Abstrak.
Dumai merupakan kawasan yang memiliki berbagai aktivitas antropogenik yang dapat mengakibatkan timbulnya tekanan terhadap ekosistem di perairan Dumai dan dapat menyebabkan perairan tidak produktif dan keanekaragaman hayati menurun. Penelitian ini bertujuan untuk mengetahui tingkat beban pencemaran di Perairan Dumai menggunakan metode purposive sampling. Hasil penelitian ini menunjukkan bahwa tingkat pencemaran tertinggi terdapat di sekitar kawasan Pangkalan Sesai dan Purnama yang kawasannya dialiri oleh Sungai Dumai. Indeks pencemaran menunjukkan status kualitas perairan Dumai telah tercemar sedang.
\end{abstract}

\begin{abstract}
.
Dumai is an area that has various anthropogenic activities that can result in pressure on the ecosystem in Dumai waters and can cause unproductive waters and decrease biodiversity. This study aims to determine the level of pollution load in Dumai waters using a purposive sampling method. The results of this study indicate that the highest level of pollution is around the Pangkalan Sesai and Purnama areas where the Dumai River flows. The pollution index indicates that the quality status of Dumai waters has been moderately polluted.
\end{abstract}

Keywords: pollution load, pollution level, Dumai Waters

Kata kunci: beban pencemaran, tingkat pencemaran, Perairan Dumai

\section{PENDAHULUAN}

Dumai merupakan salah satu kawasan yang berbatasan langsung dengan Selat Malaka yang merupakan jalur pelayaran internasional. Pertumbuhan dan perkembangan industri di Kota Dumai semakin meningkat, hal ini terlihat dari jumlah aktivitas industri yang semakin pesat sejalan dengan aktivitas antropogenik yang ada di sekitar pesisir Dumai. Aktivitas tersebut secara tidak sengaja mempengaruhi kualitas perairan yang berada di Selat Rupat hingga terjadinya penurunan kualitas perairan pesisir.

Kegiatan industri, rumah tangga dan pertanian yang dilakukan dalam pemenuhan kebutuhan hidup masyarakat pesisir memberikan sumbangan limbah yang dapat menyebabkan penurunan kualitas air (Suriawiria 2005). Kegiatan permukiman memberikan masukan bahan pencemaran ke dalam perairan. Begitu pula halnya dengan kegiatan lainnya seperti industri dan bongkar muat menyebabkan semakin tingginya kandungan bahan pencemar. Menurut Erari et al. (2012), masyarakat adalah salah satu faktor penyebab rusaknya sebuah ekosistem. Masyarakat dapat menjadi penyebab air sungai di

\footnotetext{
${ }^{*}$ Korespondensi Penulis

Email : fitriariani1791@gmail.com
} 
Dumai dan perairan Selat Rupat menjadi tercemar dan tidak produktif (Sofia et al. 2010).

Peningkatan pengembangan wilayah kota ke arah pantai dapat mempengaruhi pesatnya pertumbuhan industri, sehingga dapat menyebabkan terjadinya pencemaran laut (Roach 2005; Huang et al. 2013; Xie et al. 2013; Yao et al. 2015). Kondisi pencemaran akibat buangan limbah yang berlangsung terus menerus dan tak terkendali dapat berakibat fatal bagi kehidupan biota perairan (Chatvijitkul et al. 2017; Cheng et al. 2017; Darmian et al. 2018). Penurunan jumlah keanekaragaman dan kelimpahan hayati yang disebabkan oleh pencemaran dapat mengancam pertumbuhan ekosistem perairan (Beketov et al. 2013) dan kedepannya akan mempengaruhi pendapatan nelayan yang sumber mata pencahariannya berada di Perairan Dumai.

Agar suatu perairan tetap produktif, diperlukan adanya kontrol beban pencemaran yang masuk ke dalam perairan yang didasarkan pada sejumlah proses diantaranya ekspor polutan, sedimentasi, penguapan hidrolisis, transformasi fotokimia, oksidasi kimia, penyerapan biologi, filter-feeder, serta penyerapan polutan dalam tanah (Campolo et al. 2002; Ostroumov 2002). Berdasarkan hal tersebut, penelitian ini bertujuan menganalisis beban dan tingkat pencemaran yang terdapat di perairan Dumai.

\section{METODOLOGI}

\subsection{Lokasi penelitian}

Penelitian dilaksanakan di Perairan Dumai. Pengambilan sampel dilakukan pada empat kawasan yaitu Kelurahan Pangkalan Sesai (Sungai Dumai), Kelurahan Purnama (Sungai Mesjid), Kelurahan Bangsal Aceh (Sungai Nerbit) dan Kelurahan Lubuk Gaung (Sungai Buluhala). Setiap kawasan terdiri atas tiga stasiun (Gambar 1 dan Tabel 1). Penentuan lokasi titik sampling menggunakan Global Positioning System (GPS). 


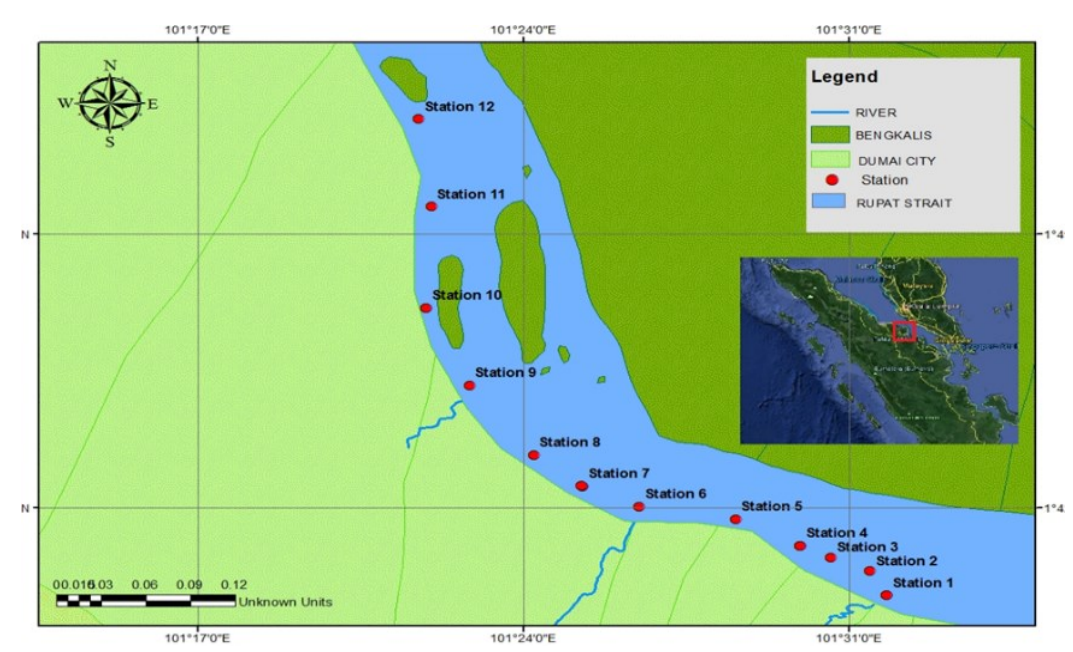

Gambar 1. Lokasi stasiun pengambilan sampel di Selat Rupat.

Tabel 1. Deskripsi lokasi pengambilan sampel.

\begin{tabular}{|c|c|c|c|c|}
\hline Lokasi & Posisi Geografis & $\begin{array}{l}\text { Nama } \\
\text { Sungai }\end{array}$ & Koordinat & Deskripsi \\
\hline 1 & $\begin{array}{l}\text { Kelurahan Pangkalan } \\
\text { Sesai (Stasiun 1, } 2 \text { dan 3) }\end{array}$ & $\begin{array}{l}\text { Sungai } \\
\text { Dumai }\end{array}$ & $\begin{array}{c}1^{\circ} 63^{\prime} 72^{\prime \prime} \mathrm{LU} \\
101^{\circ} 49^{\prime} 19^{\prime \prime} \mathrm{BT}\end{array}$ & $\begin{array}{ll}\text { - } & \text { Dok yard bongkar } \\
& \text { muat barang } \\
\text { - } & \text { Pemukiman } \\
\text { - } & \text { Dermaga kapal (bea } \\
\text { cukai, angkatan laut) } \\
\text { - } & \text { Mangrove } \\
\end{array}$ \\
\hline 2 & $\begin{array}{l}\text { Kelurahan Purnama } \\
\text { (Stasiun 4, } 5 \text { dan 6) }\end{array}$ & $\begin{array}{l}\text { Sungai } \\
\text { Mesjid }\end{array}$ & $\begin{array}{c}1^{\circ} 65^{\prime} 56^{\prime \prime} \mathrm{LU} \\
101^{\circ} 46^{\prime} 85^{\prime \prime} \mathrm{BT}\end{array}$ & $\begin{array}{ll}\text { - } & \text { Pelabuhan Bongkar } \\
& \text { Muat Ikan (TPI) } \\
\text { - } & \text { Pemukiman Penduduk } \\
\text { - } & \text { Dermaga kapal } \\
& \text { pengangkut ikan } \\
\text { - } & \text { Komunitas mangrove } \\
\text { - } & \text { Bongkar muat barang } \\
\end{array}$ \\
\hline 3 & $\begin{array}{l}\text { Kelurahan Bangsal Aceh } \\
\text { (Stasiun 7, 8 dan 9) }\end{array}$ & $\begin{array}{l}\text { Sungai } \\
\text { Nerbit }\end{array}$ & $\begin{array}{c}1^{\circ} 60^{\prime} 19^{\prime \prime} \mathrm{LU} \\
101^{\circ} 38^{\prime} 36^{\prime \prime} \mathrm{BT}\end{array}$ & - Aktivitas Industri \\
\hline 4 & $\begin{array}{l}\text { Kelurahan Lubuk Gaung } \\
\text { (Stasiun 10,11 dan 12) }\end{array}$ & $\begin{array}{c}\text { Sungai } \\
\text { Buluhala }\end{array}$ & $\begin{array}{c}1^{\circ} 70^{\prime} 21^{\prime \prime} \mathrm{LU} \\
101^{\circ} 31^{\prime} 06^{\prime \prime} \mathrm{BT}\end{array}$ & - Aktivitas Industri \\
\hline
\end{tabular}

Sumber: Data primer (2015).

\subsection{Metode pengambilan sampel}

Pengambilan sampel air dilakukan dengan menggunakan Van Dorn Water Sampler. Pengukuran parameter suhu, salinitas, pH dan DO menggunakan Water Quality Checker (WQC), sedangkan untuk analisis kimia lainnya seperti nitrat, fosfat, $\mathrm{BOD}_{5}$ dan COD dilakukan di Laboratorium Ekologi dan Pengelolaan 
Lingkungan Perairan, Universitas Riau. Metode dan alat-alat pengambilan sampel secara rinci disajikan pada Tabel 2.

Tabel 2. Metode pengambilan sampel.

\begin{tabular}{lcll}
\hline Parameter & Satuan & Metode/alat & Keterangan \\
\hline Suhu & ${ }^{\circ} \mathrm{C}$ & QI/LKA/12 (Termometer) & in-situ \\
Salinitas & $\% 0$ & Hand Refraktometer & in-situ \\
pH & - & Water Quality Checker (WQC) & in-situ \\
DO & $\mathrm{mg} / \mathrm{l}$ & Water Quality Checker (WQC) & in-situ \\
BOD $_{5}$ & $\mathrm{mg} / \mathrm{l}$ & APHA.2510 B,- 1998 & ex-situ/laboratorium \\
COD & $\mathrm{mg} / \mathrm{l}$ & QI/LKA/19 (Spektrofotometer) & ex-situ/laboratorium \\
Fosfat & $\mathrm{mg} / \mathrm{l}$ & Spektrofotometer GENESYS 10S UV VIS & ex-situ/laboratorium \\
Nitrat & $\mathrm{mg} / \mathrm{l}$ & APHA. 4500 NO2 B, 2005 & ex-situ/laboratorium \\
Minyak & $\mathrm{mg} / \mathrm{l}$ & APHA 2012 & ex-situ/laboratorium \\
TSS & $\mathrm{mg} / \mathrm{l}$ & APHA. 2540D, 2005 & ex-situ/laboratorium \\
\hline
\end{tabular}

Sumber: Data primer (2015).

\subsection{Prosedur analisis data}

Estimasi tingkat pencemaran dianalisis dengan pendekatan Rapid Assessment yaitu perhitungan beban pencemar dari setiap sumber pencemaran seperti pemukiman (jumlah populasi), restoran, aneka industri, pertanian, perikanan dan transportasi (pelayaran). Merujuk pada Djajadiningrat dan Amir (1991), analisis beban limbah dengan rapid assessment dilakukan dengan menggunakan Persamaan 1.

$B L=Q \times C$

Keterangan:

$\mathrm{BL}=$ beban pencemaran dari sebuah sungai (ton/thn)

$\mathrm{Q}=$ debit sungai $\left(\mathrm{m}^{3} /\right.$ thn $)$

$\mathrm{C}=$ konsentrasi limbah $(\mathrm{mg} / \mathrm{l})$

Total beban pencemaran dari seluruh sungai yang bermuara di Selat Rupat dihitung berdasarkan rapid assessment merujuk pada Djajadiningrat dan Amir (1991) yang dijelaskan melalui Persamaan 2.

$T B L=\sum_{i=1}^{n} B L$

Keterangan :

TBL = total beban limbah

$\mathrm{N}=$ jumlah sungai

I = beban limbah sungai ke-i

Salah satu metode penentuan status mutu air adalah menggunakan Indeks Pencemaran (IP) mengacu pada KepMenLH Nomor 115 Tahun 2003 tentang Pedoman Penentuan Status Mutu Air (Lampiran II). Metode ini dapat memberi 
masukan kepada pengambil keputusan agar dapat menilai kualitas suatu badan air untuk suatu peruntukkan tertentu, serta melakukan tindakan perbaikan kualitas air jika terjadi penurunan kualitas akibat kehadiran senyawa pencemar. Perhitungan status mutu air dengan menggunakan metode IP disampaikan pada Persamaan 3.

Pij $=\frac{\sqrt{\left(\frac{C i}{L i x}\right) R^{2}+\left(\frac{C i}{L i x}\right) M^{2}}}{2}$

Keterangan:

$(\mathrm{Ci} / \mathrm{Lix}) \mathrm{R}=$ Nilai rata-rata dari jumlah konsentrasi dari parameter yang diuji.

$(\mathrm{Ci} / \mathrm{Lix}) \mathrm{M}$ = Nilai maksimal dari hasil pembagian hasil nilai konsentrasi dengan baku mutu.

Hasil perhitungan IP dibandingkan dengan klasifikasi status mutu air sebagaimana tertera dalam KepMenLH Nomor 115 Tahun 2003 (Tabel 3), sehingga dapat diketahui status mutu air sungai tersebut.

Tabel 3. Klasifikasi status mutu air berdasarkan nilai Indeks Pencemaran (IP).

\begin{tabular}{lc}
\hline Skor & Status mutu \\
$0 \leq \mathrm{IP} \leq 1,0$ & Baik \\
$1,0<\mathrm{IP} \leq 5,0$ & Cemar ringan \\
$5,0<\mathrm{IP} \leq 10,0$ & Cemar sedang \\
$\mathrm{IP}>10,0$ & Cemar berat \\
\hline
\end{tabular}

\section{HASIL DAN PEMBAHASAN}

\subsection{Kualitas air}

Pencemaran perairan merupakan masuk atau dimasukkannya suatu zat, bahan pencemar, makhluk hidup, energi, atau komponen lainnya ke dalam air yang diakibatkan oleh aktivitas antropogenik maupun proses alami dari lingkungan itu sendiri, sehingga menurunkan fungsi kualitas suatu perairan sampai tingkat tertentu (KepMenLH Nomor 51 Tahun 2004). Berdasarkan hasil kajian, kualitas perairan Dumai tergolong cemar sedang berdasarkan pada beberapa parameter yang telah melebihi nilai ambang batas (baku mutu) air laut sesuai KepMenLH Nomor 51 Tahun 2004 (Lampiran III). Nilai-nilai parameter kualitas air hasil pengamatan pada 12 stasiun sampling di Perairan Dumai disampaikan pada Tabel 4.

Tabel 4. Kualitas air di Perairan Dumai.

\begin{tabular}{|c|c|c|c|c|c|c|c|c|c|c|c|c|c|c|}
\hline \multirow{3}{*}{ Parameter } & \multirow{3}{*}{$\begin{array}{l}\text { Baku } \\
\text { Mutu }\end{array}$} & \multirow{3}{*}{ Unit } & \multicolumn{12}{|c|}{ Titik Sampling } \\
\hline & & & \multicolumn{3}{|c|}{ Kel. Pangkalan Sesai } & \multicolumn{3}{|c|}{ Kel. Purnama } & \multicolumn{3}{|c|}{ Kel. Bangsal Aceh } & \multicolumn{3}{|c|}{ Kel. Lubuk Gaung } \\
\hline & & & 1 & 2 & 3 & 4 & 5 & 6 & 7 & 8 & 9 & 10 & 11 & 12 \\
\hline Suhu & - & ${ }^{\circ} \mathrm{C}$ & 32 & 31 & 30 & 30 & 31 & 28 & 31 & 30 & 31 & 29 & 32 & 31 \\
\hline Kecerahan & $>6$ & $\mathrm{~m}$ & 0,55 & 0,32 & 0,60 & 0,91 & 0,62 & 0,42 & 0,58 & 0,61 & 0,44 & 0,67 & 0,51 & 0,53 \\
\hline Salinitas & - & $\%$ & 19,10 & 23,30 & 30,90 & 25,10 & 28,30 & 21,80 & 22,80 & 21,20 & 26,80 & 21,30 & 20,90 & 26,60 \\
\hline
\end{tabular}




\begin{tabular}{|c|c|c|c|c|c|c|c|c|c|c|c|c|c|c|}
\hline $\mathrm{pH}$ & $7-8,5$ & - & 6,2 & 6,3 & 6,2 & 7,1 & 7,3 & 8,3 & 8,5 & 8,1 & 7,2 & 7,8 & 7,7 & 8.7 \\
\hline DO & $>5$ & $\mathrm{mg} / \mathrm{l}$ & 2,60 & 4,70 & 4,30 & 2,40 & 3,80 & 3,57 & 2,40 & 2,80 & 2,98 & 4,40 & 3,80 & 3,70 \\
\hline $\mathrm{BOD}_{5}$ & 20 & $\mathrm{mg} / \mathrm{l}$ & 48,37 & 78,90 & 96,50 & 97,35 & 77,20 & 63,87 & 74,70 & 86,80 & 57,29 & 108,10 & 154,30 & 101,30 \\
\hline COD & - & $\mathrm{mg} / \mathrm{l}$ & 178,60 & 167,04 & 189,30 & 167,20 & 176,32 & 138,32 & 179,36 & 177,84 & 162,64 & 186,80 & 148,80 & 142,90 \\
\hline Fosfat & 0,015 & $\mathrm{mg} / \mathrm{l}$ & 0,11 & 0,25 & 0,15 & 0,15 & 0,14 & 0,39 & 0,13 & 0,03 & 0,04 & 0,13 & 0,10 & 0,10 \\
\hline Nitrat & 0,008 & $\mathrm{mg} / \mathrm{l}$ & 0,74 & 1,33 & 0,42 & 0,90 & 1,03 & 1,91 & 0,70 & 0,82 & 0,72 & 0,85 & 1,89 & 1,97 \\
\hline Minyak & 1 & $\mathrm{mg} / \mathrm{l}$ & 0,327 & 0,213 & 0,434 & 0,436 & 0,332 & 0,386 & 0,49 & 0,48 & 0,46 & 0,642 & 0,719 & 0,537 \\
\hline TSS & 400 & $\mathrm{mg} / \mathrm{l}$ & 56,10 & 38,10 & 43,50 & 39,70 & 40,20 & 46,90 & 47,40 & 49,50 & 44,20 & 41,10 & 37,10 & 46,40 \\
\hline
\end{tabular}

Sumber: Data primer (2015).

\subsubsection{Derajat keasaman (pH)}

Pengolahan air untuk perbaikan kualitas air dapat dilihat berdasarkan nilai derajat keasaman suatu perairan (Kordi dan Tancung 2007). Perairan Dumai memiliki nilai derajat keasaman ( $\mathrm{pH}$ ) stabil dengan nilai kisaran 6,2-8,7. Hasil ini menunjukkan bahwa perairan Dumai masih berada dalam kisaran yang dapat diterima oleh organisme akuatik. Setiap jenis organisme memiliki nilai derajat keasaman yang berbeda-beda (Cech 2005). Ikan yang hidup di perairan dengan pH tinggi memiliki kandungan amonia lebih tinggi dibandingkan dengan ikan yang hidup di perairan tawar (Tiwary et al. 2013).

Perubahan $\mathrm{pH}$ perairan dapat mempengaruhi proses pelarutan dan presipitasi partikel-partikel sedimen. Menurut Rifardi (2008), proses pengendapan (sedimentasi) di perairan dipengaruhi oleh proses-proses kimia. Hal ini berdampak buruk terhadap kehidupan biota laut karena $\mathrm{pH}$ merupakan salah satu parameter dari tingginya produktivitas primer perairan.

\subsubsection{DO (dissolved oxygen)}

Oksigen terlarut merupakan parameter penting yang diperlukan oleh semua organisme yang ada di perairan. Berkurangnya kandungan oksigen terlarut dalam perairan akan sangat mengganggu dan berbahaya bagi kehidupan organisme akuatik. Oksigen yang terisi pada badan air dengan cara kontak langsung dengan atmosfer merupakan hal yang sangat penting karena atmosfer berkontribusi terhadap sebagian besar oksigen dalam air (Achmad 2004).

Konsentrasi DO tertinggi terdapat di kawasan Kelurahan Pangkalan Sesai stasiun 2 yakni sebesar 4,70 mg/l, sedangkan konsentrasi terendah terdapat pada kawasan Kelurahan Purnama stasiun 4 dan kelurahan Bangsal Aceh stasiun 7 yakni sebesar 2,40 mg/l. Proses fotosintesis dan absorbsi dari udara menjadi penyebab terjadinya fluktuasi konsentrasi DO di perairan Salmin (2000). Pada kasus kondisi anaerobik, oksigen yang dihasilkan akan mereduksi senyawasenyawa kimia menjadi lebih sederhana dalam bentuk nutrien dan gas. Semakin banyak jumlah DO, maka kualitas air semakin baik, sebaliknya bila kadar DO terlalu rendah akan timbul aroma yang tidak sedap akibat terjadinya degradasi anaerobik (Salmin 2000). 


\subsection{3. $\mathrm{BOD}_{5}$}

Tingkat pencemaran bahan organik pada air limbah dapat dicirikan dari tingkat BOD 5 perairan. Tingginya bahan organik dapat menyebabkan mikroba menjadi aktif dan menguraikannya menjadi senyawa asam-asam organik. Proses penguraian ini terjadi secara aerob dan anaerob yang menghasilkan gas $\mathrm{CH}_{4}$, $\mathrm{NH}_{3}$ dan $\mathrm{H}_{2} \mathrm{~S}$ yang berbau tidak sedap (Djarwanti et al. 2000).

Secara umum konsentrasi BOD 5 yang terdapat di Perairan Dumai telah melebihi nilai baku mutu yang ditetapkan oleh KepMenLH Nomor 51 Tahun 2004 untuk biota laut. Konsentrasi BOD $_{5}$ terendah terdapat di kawasan Kelurahan Pangkalan Sesai Stasiun 1 (48,37 mg/l) dan konsentrasi tertinggi terdapat pada kawasan Lubuk Gaung Stasiun 11 (154,30 mg/l). Tingginya kandungan BOD $_{5}$ pada kawasan-kawasan tersebut disebabkan tingginya kandungan limbah organik yang berasal dari daratan sekitar perairan (aktivitas antropogenik dan aktivitas industri). Nilai $\mathrm{BOD}_{5}$ yang tinggi akan mempengaruhi proses aerobik, karena oksigen tidak dapat mengoksidasi bahan-bahan organik dan non organik. Konsentrasi oksigen yang rendah dapat mengakibatkan kematian massal pada bakteri aerob (Susana dan Suyarso 2008).

\subsubsection{TSS (total suspended solid)}

Padatan tersuspensi total merupakan bahan yang tersuspensi di dalam air yang terdiri dari lumpur, pasir halus dan jasad-jasad renik (Effendi 2003). Semua perubahan yang tampak pada perairan berhubungan dengan material tersuspensi dan material yang terlarut di dalam air (Selanno 2009).

Total suspended solid atau padatan tersuspensi di perairan Dumai berkisar 37,10-56,10 mg/l. Kandungan TSS terendah berada di Stasiun 11 Kelurahan Lubuk Gaung dan tertinggi terdapat pada stasiun 1 di Kelurahan Pangkalan Sesai. Kelurahan Pangkalan Sesai merupakan kawasan yang dipadati oleh kegiatan antropogenik. Limbah-limbah tersebut mengalir langsung ke Perairan Dumai, sehingga menyebabkan kandungan TSS pada kawasan tersebut lebih tinggi dibandingkan lokasi lainnya. Hal ini sesuai dengan pernyataan Sami (2012), pada umumnya limbah yang digunakan oleh masyarakat dibuang langsung ke saluran umum yang berhubungan langsung dengan perairan.

\subsubsection{Minyak}

Aktivitas industri minyak merupakan salah satu penghasil limbah yang menyumbang pencemaran di laut. Secara umum kandungan minyak di perairan Dumai masih berada di bawah baku mutu yang ditetapkan oleh KepMenLH Nomor 51 Tahun 2004 untuk biota laut. Konsentrasi minyak terendah berada di lokasi Stasiun 2 Kelurahan Pangkalan Sesai $(0,213 \mathrm{mg} / \mathrm{l})$ yang merupakan area pemukiman penduduk di sekitar kawasan hutan mangrove. Konsentrasi tertinggi terdapat pada stasiun 11 Kelurahan Lubuk Gaung $(0,719 \mathrm{mg} / \mathrm{l})$ yang 
merupakan kawasan padat industri. Pencemaran minyak dapat mengganggu proses reproduksi, pertumbuhan dan perilaku biota laut, serta berdampak pada pengembangan ekosistem (Yamamoto et al. 2003). Pada hal kronisnya, pencemaran minyak dapat berdampak langsung pada kematian organisme laut (Sulistyono 2013).

\subsection{Beban pencemaran}

Analisis beban pencemaran merupakan analisis hubungan antara besarnya beban pencemaran (pollution load) dari masing-masing pencemar dengan konsentrasi pencemar di laut (Selanno 2009). Polutan yang berasal dari kegiatan pertanian, peternakan, limbah perkotaan dan limbah industri yang langsung masuk ke dalam aliran permukaan dapat menyebabkan pencemaran lingkungan perairan (Campolo et al. 2002). Nilai beban pencemar yang masuk ke dalam perairan Dumai disajikan pada Tabel 5.

Perhitungan beberapa beban pencemaran air sungai didasarkan pada besaran konsentrasi masing-masing unsur pencemar dan debit air sungai (Hamakonda et al. 2019). Sungai Mesjid yang berada di Kelurahan Purnama memberikan kontribusi terbesar terhadap beban pencemaran pada setiap parameternya yaitu $\mathrm{NO}_{3}$ sebesar 6,303 kg/hari, $\mathrm{PO}_{4}$ sebesar 1,280 kg/hari, BOD sebesar 211,326 kg/hari, COD sebesar 457,657 kg/hari, TSS sebesar 155,177 $\mathrm{kg}$ /hari dan minyak sebesar 3,309 kg/hari. Hal ini disebabkan oleh besarnya debit air dan berbagai kegiatan yang dilakukan di Sungai Mesjid seperti bongkar muat sawit, bahan makanan pokok, serta tempat berlabuhnya kapal-kapal.

Tabel 5. Rata-rata konsentrasi beban pencemar yang berasal dari sungai.

\begin{tabular}{clrrrrrr}
\hline \multirow{2}{*}{ No. } & \multirow{2}{*}{ Nama sungai } & \multicolumn{5}{c}{ Nilai beban pencemaran (kg/hari) } \\
\cline { 2 - 7 } & & $\mathrm{NO}_{3}$ & $\mathrm{PO}_{4}$ & $\mathrm{BOD}$ & $\mathrm{COD}$ & $\mathrm{TSS}$ & Minyak \\
\hline 1 & Sungai Dumai & 1,277 & 0,195 & 83,583 & 308,621 & 96,941 & 1,728 \\
2 & Sungai Mesjid & 6,303 & 1,280 & 211,326 & 457,658 & 155,177 & 3,309 \\
3 & Sungai Nerbit & 1,175 & 0,060 & 93,497 & 265,428 & 72,134 & 1,632 \\
4 & Sungai Buluhala & 5,626 & 0,280 & 289,313 & 408,122 & 132,518 & 2,856 \\
\hline
\end{tabular}

Beberapa bahan pencemar yang masuk ke dalam perairan merupakan bahan pencemar dari kegiatan industri dan limbah domestik baik itu pertanian, perkebunan, serta limbah rumah tangga. Berdasarkan Tabel 6, beban pencemaran tertinggi dari kegiatan industri berasal dari perusahaan $\mathrm{C}$ yang bergerak di bidang pengolahan industri minyak dan tangki timbun. Perusahaan C yang berlokasi di Lubuk Gaung secara tidak langsung mempengaruhi tingkat beban pencemaran di sekitar Sungai Buluhala yang merupakan salah satu sungai terpanjang di Dumai. Limbah yang masuk secara berlebihan ke dalam perairan dapat mempengaruhi kemampuan lingkungan dalam menampung beban 
pencemaran. Hal ini sesuai dengan pernyataan Barcelo and Petrovic (2007) yang menyatakan bahwa kemampuan lingkungan dalam menampung beban pencemaran dapat dilihat berdasarkan aktivitas yang terdapat di sekitarnya, serta berapa besar parameter kimia dan bahan organik yang sudah masuk ke dalam perairan seperti parameter $\mathrm{NO}_{3}{ }^{-}, \mathrm{PO}_{4}^{3-}, \mathrm{BOD}$, $\mathrm{COD}$ dan TSS.

Tabel 6. Beban pencemaran yang berasal dari industri.

\begin{tabular}{clrrrrr}
\hline \multirow{2}{*}{ No } & \multirow{2}{*}{ Nama perusahaan } & \multicolumn{5}{c}{ Nilai beban pencemaran (kg/hari) } \\
\cline { 3 - 6 } & & $\mathrm{PO}_{4}$ & BOD $_{5}$ & COD & TSS & Minyak \\
\hline 1 & Perusahaan A & 0 & 0,57 & 2,69 & 3,05 & 0,08 \\
2 & Perusahaan B & 0,053 & 0,0084 & 0,068 & 0,002 & 0 \\
3 & Perusahaan C & 0,006 & 4,881 & 21,87 & 20,18 & 0,42 \\
\hline
\end{tabular}

Sumber: Data Sekunder (2014).

\subsection{Indeks pencemaran (IP)}

Indeks Pencemaran digunakan untuk mengetahui status mutu sebuah perairan. Indeks Pencemaran yang bernilai kurang dari 1 memiliki kriteria baik sekali, sedangkan yang bernilai lebih dari 1 menunjukkan indikasi terjadinya pencemaran. Berdasarkan hasil analisa dengan menggunakan beberapa parameter air $\left(\mathrm{pH}, \mathrm{DO}, \mathrm{BOD}_{5}, \mathrm{COD}\right.$, nitrat dan fosfat) untuk menghitung nilai indeks pencemaran, diketahui bahwa secara umum tingkat pencemaran di perairan Dumai termasuk kategori tercemar ringan hingga sedang (Gambar 2).

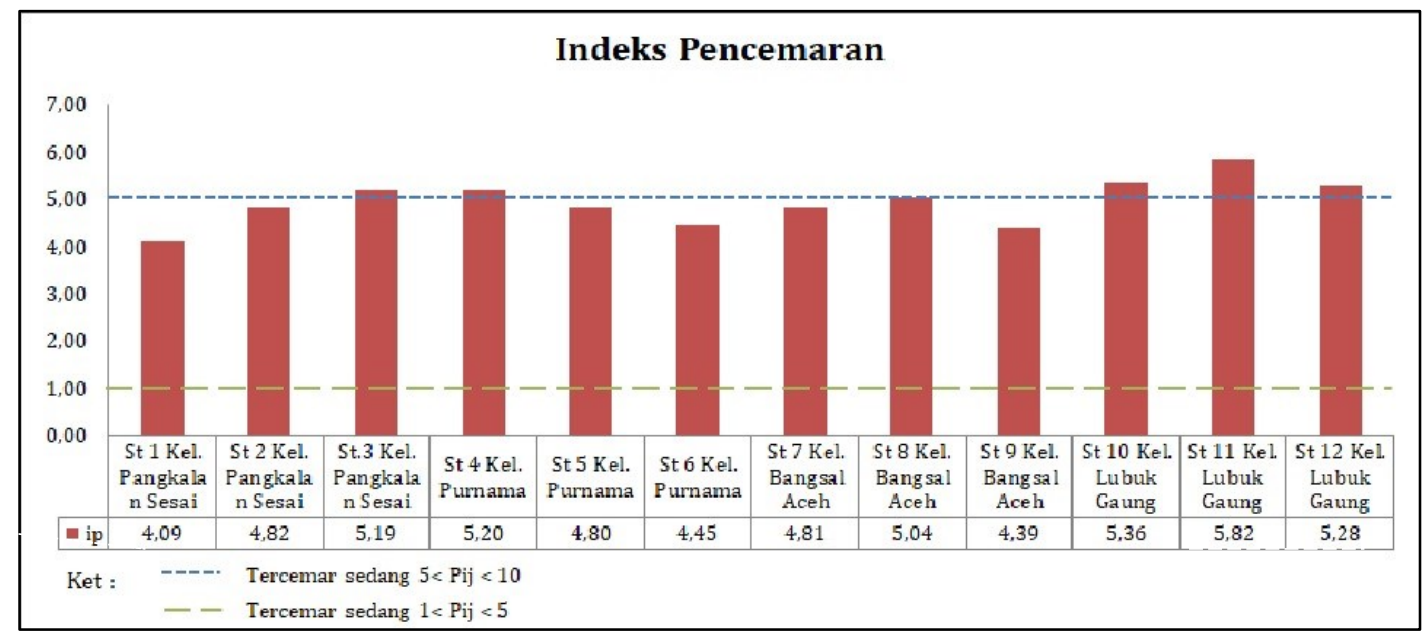

Gambar 2. Nilai indeks pencemaran di Perairan Dumai.

Beberapa lokasi yang memiliki tingkat pencemaran sedang terdapat pada stasiun 3 di Kelurahan Pangkalan Sesai, stasiun 4 di Kelurahan Purnama dan seluruh stasiun di Kelurahan Lubuk Gaung. Lokasi stasiun 4 di Kelurahan Purnama merupakan kawasan bongkar muat kapal pengangkut barang dan ikan, 
serta merupakan kawasan pemukiman padat penduduk yang diduga dapat mempengaruhi kualitas air di wilayah tersebut. Stasiun-stasiun di Kelurahan Lubuk Gaung merupakan lokasi dengan aktivitas padat industri. Lokasi-lokasi lainnya memiliki tingkat pencemaran terjadi masih tergolong tercemar ringan. Hal ini berarti perairan Dumai sudah berada dalam batas kemampuannya dalam menampung limbah pencemaran yang terdapat di dalamnya.

\section{KESIMPULAN}

Beban pencemaran perairan yang terdapat di perairan Dumai dipengaruhi oleh kegiatan yang ada di sekitarnya, baik dari daratan maupun perairan itu sendiri. Beban pencemaran tertinggi berasal dari Sungai Mesjid yang merupakan salah satu sungai terbesar yang mengalir di sepanjang kota Dumai dengan aktivitas seperti bongkar muat barang, pemukiman, serta pertanian.

Indeks Pencemaran (IP) menunjukkan bahwa status kualitas perairan Dumai pada beberapa lokasi penelitian telah tercemar sedang dengan nilai IP di atas 5. Indeks pencemaran yang terdapat di Kelurahan Lubuk Gaung telah tercemar sedang karena Kelurahan Lubuk Gaung merupakan salah satu kawasan industri aktif yang terdapat di Dumai. Sumber pencemar di Kelurahan Lubuk Gaung dibedakan menjadi sumber pencemar point source (aktivitas industri) dan non point source (aktivitas permukiman). Limbah pabrik yang masuk secara terus menerus ke dalam perairan Dumai dapat menyebabkan tekanan terhadap lingkungan, hal ini dapat dilihat pada tingginya beban pencemaran yang terjadi di kelurahan ini yang selaras dengan status mutu yang dimilikinya. Hal ini bukan hanya akan berdampak pada kesehatan organisme yang hidup, namun juga bagi kesehatan manusia yang memanfaatkan sumber daya laut tersebut.

\section{UCAPAN TERIMAKASIH}

Penelitian ini dilakukan dan dibantu oleh Laboratorium Ekologi dan Pengelolaan Lingkungan Perairan, Universitas Riau.

\section{DAFTAR PUSTAKA}

Achmad R. 2004. Kimia lingkungan edisi 1. Andi Offset. Yogyakarta.

Barceló D and Petrovic M. 2007. Challenges and achievements of LC-MS in environmental analysis: 25 years on. TrAC Trends in Analytical Chemistry 26(10):2-11.

Beketov MA, Kefford BJ, Schäfer RB and Liess M. 2013. Pesticides reduce regional biodiversity of stream invertebrates. PNAS 110(27):11039-11043.

Campolo M, Andreussi P and Soldati A. 2002. Water quality control in the River Arno. Water Research 36(2002):2673-2680. 
Cech TV. 2005. Principles of water resources: history, development, management, and policy 2nd Ed. John Wiley \& Sons. Hoboken.

Chatvijitkul S, Boyd CE and McNevin AA. 2017. Pollution potential indicators for feed-based fish and shrimp culture. Aquaculture 477(1):43-49

Cheng WYY, Liu Y, Bourgeois AJ, Wu Y and Haupt SE. 2017. Short-term wind forecast of a data assimilation/weather forecasting system with wind turbine anemometer measurement assimilation. Renewable Energy 107:340-351.

Darmian MD, Monfared AAH, Azizyan G, Snyder SA and Giesy JP. 2018. Assessment of tools for protection of quality of water: uncontrollable discharges of pollutants. Ecotoxicology and Environmental Safety 161:190197.

Djajadiningrat ST dan Amir H. 1991. Penilaian secara cepat sumber-sumber pencemaran air, tanah, dan udara. Gadjah Mada University Press. Yogyakarta.

Djarwanti, Sartamtomo dan Sukani. 2000. Pemanfaatan energi hasil pengolahan limbah cair industri tahu. Jurnal Kimia Sains dan Aplikasi 3(2):66-70.

Effendi H. 2003. Telaah kualitas air bagi pengolahan sumberdaya dan lingkungan perairan. Yogyakarta. Kanisius.

Erari SS, Mangimbulude J dan Lewerissa K. 2012. Pelestarian hutan mangrove solusi pencegahan pencemaran logam berat di perairan Indonesia. Seminar Nasional VIII Pendidikan Biologi (SEMBIO) 182-186.

Hamakonda UA, Suharto B dan Susanawati LD. 2019. Analisis kualitas air dan beban pencemaran air pada sub DAS Boentuka Kabupaten Timor Tengah Selatan. Jurnal Teknologi Pertanian Andalas 23(1):56-67

Huang L, Ban J, Han YT, Yang J and Bi J. 2013. Multi-angle indicators system of non-point pollution source assessment in rural areas: a case study near Taihu Lake. Environmental Management 51:939-950. https://doi.org/10.1007/ s00267-013-0024-x.

KepMenLH (Keputusan Menteri Lingkungan Hidup) Nomor 115 Tahun 2003 tentang pedoman penentuan status mutu air laut.

KepMenLH (Keputusan Menteri Lingkungan Hidup) Nomor 51 Tahun 2004 tentang baku mutu air laut.

Kordi MGHK dan Tancung AB. 2007. Pengelolaan kualitas air dalam budi daya perairan. Penerbit Rineka Cipta. Jakarta

Ostroumov SA. 2002. Polyfunctional role of biodiversity in processes leading to water purification: current conceptualizations and concluding remarks. Hydrobiologia 469:203-204

Rifardi. 2008. Ekologi sedimen laut modern. Unri Press. Pekanbaru.

Roach JA. 2005. Enhancing maritime security in the Straits of Malacca and Singapore. Journal of International Affairs. 59(1):97-116. 
Salmin. 2000. Kadar oksigen terlarut di perairan Sungai Dadap, Goba, Muara Karang dan Teluk Banten. In: Praseno DP, Rositasari R dan Riyono SH (Eds.). 2000. Foraminifera sebagai Bioindikator Pencemaran. Hasil Studi di Perairan Estuarin Sungai Dadap, Tangerang. P3O-LIPI. Jakarta.

Sami. 2012. Penyisihan COD, TSS, dan $\mathrm{pH}$ dalam limbah cair domestik dengan metode fixed-bed coloumn up flow. Jurnal Teknik Kimia Politeknik Negeri Lhokseumawe 10(21):1-11.

Selanno DAJ. 2009. Analisis hubungan antara beban pencemaran dan konsentrasi limbah sebagai dasar pengelolaan kualitas lingkungan perairan Teluk Ambon Dalam [Disertasi]. Program Pascasarjana, IPB University. Bogor.

Sofia Y, Tontowi dan Rahayu S. 2010. Penelitian pengolahan air sungai yang tercemar oleh bahan organik. Jurnal Sumber Daya Air 6(2):145-160.

Sulistyono. 2013. Dampak tumpahan minyak (oil spill) di perairan laut pada kegiatan industri migas dan metode penanggulangannya. Forum Teknologi $3(1): 49-57$.

Suriawiria U. 2005. Air dalam kehidupan dan lingkungan yang sehat. PT Alumni. Bandung.

Susana T dan Suyarso. 2008. Penyebaran fosfat dan deterjen di perairan pesisir dan luar Cirebon Jawa Barat. OLDI 34(1):117-131

Tiwary CB, Pandey VS and Ali F. 2013. Effect of pH on growth performance and survive rate of Grass Carp. Biolife Journal 1(4):172-175.

Xie RR, Pang Y, Li Z, Zhang NH and Hu FJ. 2013. Eco-compensation in multidistrict river networks in North Jiangsu, China. Environmental Management 51:874-881. https://doi.org/10.1007/s00267-012-9992-5.

Yamamoto T, Nakaoka M, Komatsu T and Kawai H, Takeno MLRG and Ohwada K. 2003. Impacts by heavy-oil spill from the Russian tanker nakhodka on intertidal ecosystems: recovery of animal community. Marine Pollution Bulletin 47(1-6):91-98.

Yao H, Qian X, Yin H, Gao Ha and Wang Y. 2015. Regional risk assessment for point source pollution based on a water quality model of the Taipu River, China. Risk Analysis 35(2):265-277. https://doi.org/10.1111/risa.12259. 